\title{
Youtube Sebagai Media Pembelajaran Daring Pada Materi Syair Pelajaran Bahasa Indonesia
}

\author{
Dwi Jonanda Putri \\ E-mail: dwi.jonanada2456@student.unri.ac.id \\ *Program Studi Pendidikan Bahasa dan Sastra Indonesia, Universitas Riau
}

\section{Pengantar}

Pelaksanaan proses pembelajaran di dalam kelas dilaksanakan dan dipengaruhi oleh berbagai faktor diantaranya peserta didik, tenaga pendidik, dan sarana pendukung. Sehingga dalam pelaksanaannya ketercapaian tujuan pembelajaran dapat terlaksana dengan maksimal. Tenaga pendidik tentu ingin informasi dari yang disampaikan dapat dipahami peserta didik. Namun, kenyataan yang dihadapi justru berbanding terbalik dengan yang ada.

Memperhatikan fakta yang muncul, tentunya kefektifan suatu proses pembelajaran jarang sekali dapat tercapai dengan baik. Persoalan pendidikan, khususnya yang berkenaan dengan mutu atau kualitas pendidikan ini menyangkut terselenggaranya mutu proses dan hasil pendidikan. Mutu proses pendidikan dan pembelajaran ini perlu diselaraskan dengan standar proses yang ada.

Pembelajaran yang efektif biasanya ditandai dan diukur oleh tingkat ketercapaian tujuan oleh sebagian besar siswa. Tingkat ketercapain itu berarti pula menunjukkan bahwa sejumlah pengalaman belajar secara internal dapat diterima oleh para siswa. Dengan demikian, pembelajaran yang efektif itu tidak bisa dilepaskan dari pembelajaran yang berkualitas karena kualitas hasil belajar itu tergantung pada efektivitas pembelajaran yang terjadi atau diterjadikan di dalam proses pembelajaan itu sendiri.

Perlu adanya inovasi dalam pelaksanaan kegiatan pembelajaran dengan memanfaatkan berbagai media baik itu media online maupun media bentuk fisik sebagai bentuk menarik kembali perhatian peserta didik. Terlebih lagi peserta didik dijenjang sekolah menengah pertama masih sangat terobsesi dengan 
kegiatan bermain. Maka perlu dirancang kegiatan belajar yang menyenangkan sehingga peserta didik bisa menerima materi secara maksimal.

Penulis membuat tulisan ini dengan merujuk pada pelaksanaan pembelajaran bahasa Indonesia dengan menggunakan materi sayir. penulis bertujuan agar pelaksanaan pembelajaran daring dapat terlaksana dengan optimal sehingga peserta didik dapat menyerap ilmu dengan sebaik-baiknya.

\section{Tindakan yang Dilakukan}

Perlu adanya tindakan nyata agar pembelajaran teks tanggapan ini dapat terlaksana dengan baik. Guru yang baik mampu menyusun model pembelajaran yang sistematis sehingga tidak terjadi penyelewengan proses dari pembelajaran. Penulis menyusun sistematis tindakan menjadi tiga bagian yakni pendahuluan, inti, dan penutup.

Pendahuluan merupakan tahap mengecek kesiapan peserta didik dengan melakukan do'a bersama sebelum kelas dimulai. Setelah membaca do'a bersama guru mengecek kehadiran dan dilanjutkan dengan pengenalan materi sehingga peserta didik dapat gambaran terkait bahasan. Dari sana, muncul rasa ingin tahu dari peserta didik dan guru melemparkan pertanyaan ringan tentang materi syair yang dikaittkan dengan kehidupan nyata.

Selanjutnya pada proses inti pembelajaran guru menklarifikasi masalah yang muncul dari materi ini. Dengan mencontohkan serta mengajarkan kepada peserta didik cara bersyair dengan baik. Dengan ini, peserta didik mampu termotivasi untuk mempraktekkan dan mempelajari lebih dalam cara bersyair.

Pada bagian penutup guru memberikan refleksi berupa tugas membuat resume individu sebagai pelatihan ketrampilan. Kemudian, direalisasikan serta dipublikasikan dalam bentuk video youtube sebagai tugas pula menggunakan media tersebut.2q Guru memberikan penguatan materi dan arahan untuk mencari referensi terkait baik melalui buku, perpustakaan maupun yang tersedia diinternet.

\section{Sarana Pendukung}


Tak hanya tindakan yang diperlukan dalam pelakanaan belajar mengajar, tetapi sarana pendukung yang juga turut menjadi unsur penting dalam menciptakan suasana pembelajaran yang efektif pada mata pelajaran bahasa Indonesia. Sarana pendukung tersebut antara lain:

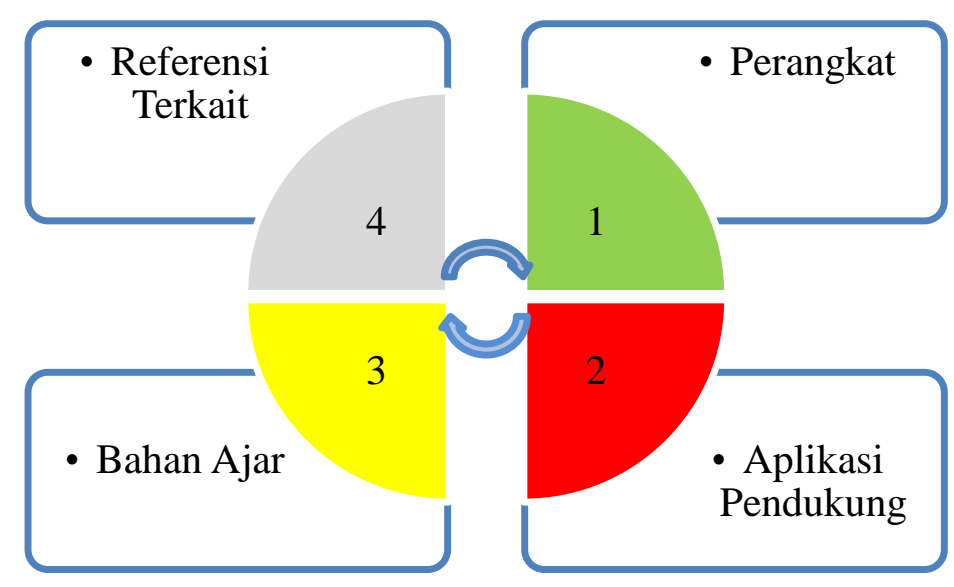

Gambar 1. Sarana Pendukung Pembelajaran Syair.

1. Perangkat, dalam pelaksanaan pembelajaran daring perangkat merupakan saran pertama yang harus di siapkan seorang tengana pendidik, perangkat ini dapat berupa computer atau laptop, kuota internet serta jaringan internet yang memadai. Sehingga proses pembelajaran dapat terlaksana dengan baik.

2. Aplikasi Pendukung, penggunaan aplikasi merupakan sarana umum yang sering digunakan guru dalam melaksanakan kegiatan pembelajaran, dapat berupa aplikasi Google classroom, Google meet atau zoom, dan beberapa aplikasi lain yang dapat digunakan.

3. Bahan ajar, sebagai seorang guru tentulah harus menyiapkan bahan ajar untuk digunakan dalam menyampaikan materi terkait. Bahan ajar ini merupakan sumber utama dari pembelajaran berupa, buku ajar.

4. Situs-situs Internet, selain bahan ajar guru juga harus mempersiapkan bahan ajar berupa referensi-referensi dari internet sehingga pembelajaran tidak berjalan monoton dan membosankan dan pelakasanaan pembelajaran dapat dilakukan dengan maksimal.

\section{Tindakan Solutif}

Selain sarana pendukung, guru bahasa Indonesia harus mampu sigap dalam menghadapai kendala dalam proses pelaksanaan pembelajaran . Guru harus 
mampu menyiapkan solusi terhadap kemungkinan-kemungkinan yang dapat menjadi penghalang dalam proses pembelajaran. Diantaranya:

1. Whatssapp/Telegram/Google classroom

2. Youtube

3. Email

4. Website Pendidikan

5. Warnet/ Wifi gratis

6. Buku/Model

\section{Simpulan}

Pembelajaran bahasa Indonesia khusunya dalam materi syair perlu ditemukan model pembelajaran yang efektif sehingga peserta didik dapat menerima materi secara optimal. Dalam pelaksanaan pembelajaran teks tanggapan dapat dengan tindakan merancang sistematis pelaksanaan pembelajaran sehingga terarah, seperti pendahuluan dengan membuka kelas secara komunikatif, inti yakni memberikan keleluasaan peserta didik dalam memecahkan masalah, dan penutup dengan memberikan refleksi sehingga materi dapat diterima dengan baik.

Selain dibarengi tindakan juga harus mempersiapkan sarana pendukung dan penyelesaian saat menemukan kendala dalam proses pelaksanaan pembelajaran. Saran pendukung antara lain Perangkat, Aplikasi Pendukung, Bahan Ajar, Situs-situs Internet. Namun, pasti akan menemukan kendala terkait sarana pendukung tersebut Whatssapp/Telegram/Google classroom, Youtube, Email, Website Pendidikan, Warnet/ Wifi gratis,Buku/Model 


\section{Referensi}

Mustafa, M. N., \& Zulhafizh, Z. (2018). Information Mastery By Teachers As A Strategy To Succeed In The Implementation Of Teaching And Learning Activities. In International Seminar and Annual Meeting BKS-PTN Wilayah Barat 2018 (pp. 516-523), Palembang.

Mustafa, M. N., \& Zulhafizh. (2017). Building the Professionalism of Teachers as an Effort to Improve Education. In Husein, R, et al (Eds.), International Seminar and Annual Meeting 2017 Fields of Linguistics, Literature, Arts, and Culture, Medan, 449.

Noorfitriana, Y., Ghazali, A. S., \& Hasanah, M. (2018). Bahan Ajar Berbasis Performansi Madihin Kreatif untuk Meningkatkan Keterampilan MenulisBerbicara Syair Siswa SMP. Jurnal Pendidikan: Teori, Penelitian, dan Pengembangan, 3(12), 1639-1643.

Reliyanti, P., \& Fuad, M. (2016). PENGEMBANGAN MATERI PEMBELAJARAN MENULIS PUISI BERBASIS NILAI KARAKTER SYAIR LAGU-LAGU KERONCONG GESANG. J-Simbol (Bahasa, Sastra, dan Pembelajarannya), 4(1). 
*Data Penulis

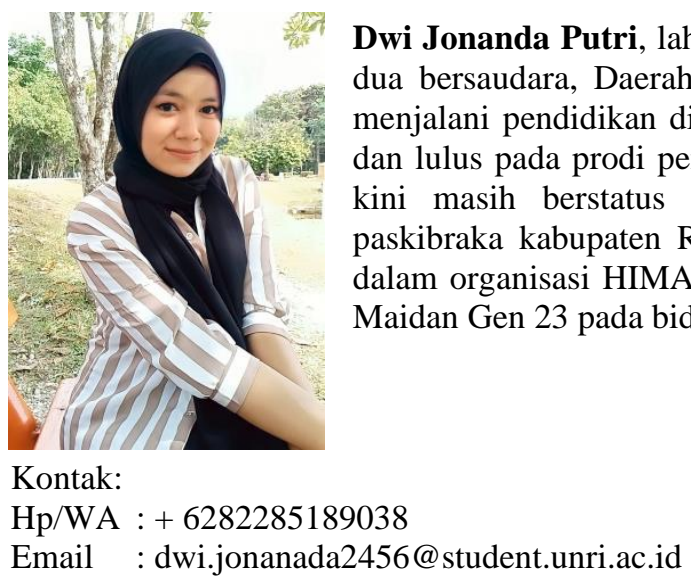

